\title{
Dificuldades do enfermeiro na atenção básica no cuidado às pessoas que vivem com HIV/AIDS
}

\author{
Difficulties of nurses in basic care for people living with HIV/AIDS \\ Dificultades de las enfermeras en la atención básica para personas que viven con VIH / SIDA
}

\section{Resumo}

O vírus da imunodeficiência humana (HIV) é uma infecção sexualmente transmissível (IST) que atinge, principalmente, o sistema imunológico, afetando diversas pessoas no mundo, configurando então, um problema de saúde de publica. $\mathrm{Na}$ atenção primaria ocorre o primeiro contato entre enfermeiro e paciente, promovendo então, um atendimento com orientações claras sobre o vírus do HIV/Aids. Objetivo: foi analisar através de uma revisão de literatura as principais dificuldades na assistência de enfermagem às PVHIV na atenção básica. Metodologia: trata-se de uma revisão de literatura integrativa do tipo explicativa, de caráter qualitativo, realizada no período entre agosto de 2020 e maio de 2021, apresentando nas bases de dados da Plataforma da Biblioteca Virtual em Saúde (BVS) indexados nas bases de dados, Scientific Eletronic Library Online (SCIELO), Literatura Latino-Americana e do Caribe em Ciências da Saúde (LILACS) Medical Literature Analysis and Retrieval System Online (MEDLINE). Foram incluídos estudos qualitativos e quantitativos, publicados nos últimos 10 anos no Brasil, com textos completos e disponíveis na integra e excluídos sem relevância para a temática e repetidos nas bases de busca. Após a leitura detalhada, foram selecionados 15 artigos para elaboração do estudo. Resultados: o estudo obteve dados que descrevem as dificuldades ao cuidado do enfermeiro as PVHIV, realizados em diferentes regiões do Brasil (Norte, Nordeste, Sul e Sudeste). Conclusão: Sendo assim os artigos mostram as falhas do sistema público frente a atenção primaria em que estão ligados a logística de insumos e matérias limitando a assistência e prejudicando o acesso de um serviço de qualidade.

Palavras-chave: Atenção primaria a saúde; Enfermagem, Diagnostico; HIV.

\begin{abstract}
The human immunodeficiency virus (HIV) is a sexually transmitted infection (STI) that mainly affects the immune system, affecting several people in the world, thus constituting a public health problem. In primary care, there is the first contact between nurse and patient, promoting, then, a service with clear guidelines on the HIV / AIDS virus. Objective: to analyze through a literature review the main difficulties in nursing care for PLHIV in primary care. Methodology: this is an integrative literature review of an explanatory type, of a qualitative character, carried out between August 2020 and May 2021, presenting in the databases of the Virtual Health Library (VHL) platform indexed in the databases. data, Scientific Eletronic Library Online (SCIELO), Latin American and Caribbean Literature in Health Sciences (LILACS) Medical Literature Analysis and Retrieval System Online (MEDLINE). Qualitative and quantitative studies were published, published in the last 10 years in Brazil, with complete texts and available in full and excluded without relevance to the theme and repeated in the search bases. After detailed reading, 15 articles were selected for the preparation of the study. Results: the study obtained data that describe the difficulties in nursing care for PLHIV, carried out in different regions of Brazil (North, Northeast, South and Southeast). Conclusion: Therefore, the articles show the failures of the public system in relation to the primary care in which they are linked to the logistics of inputs and materials, limiting assistance and impairing access to a quality service.
\end{abstract}

Keywords: Primary health care; Nursing; Diagnosis; HIV.

\section{Resumen}

El virus de la inmunodeficiencia humana (VIH) es una infección de transmisión sexual (ITS) que afecta principalmente al sistema inmunológico, afectando a varias personas en el mundo, constituyendo así un problema de salud pública. En atención primaria, se da el primer contacto entre enfermera y paciente, promoviendo, luego, un servicio con pautas claras sobre el virus VIH / SIDA. Objetivo: analizar a través de una revisión de la literatura las 
principales dificultades en la atención de enfermería a las PVVIH en atención primaria. Metodología: se trata de una revisión integradora de la literatura de tipo explicativo, de carácter cualitativo, realizada entre agosto de 2020 y mayo de 2021, presentándose en las bases de datos de la Plataforma de la Biblioteca Virtual en Salud (BVS) indexadas en las bases de datos. Biblioteca electrónica en línea (SCIELO), Literatura latinoamericana y caribeña en ciencias de la salud (LILACS) Sistema de análisis y recuperación de literatura médica en línea (MEDLINE). Se publicaron estudios cualitativos y cuantitativos, publicados en los últimos 10 años en Brasil, con textos completos y disponibles en su totalidad y excluidos sin relevancia para el tema y repetidos en las bases de búsqueda. Luego de una lectura detallada, se seleccionaron 15 artículos para la elaboración del estudio. Resultados: el estudio obtuvo datos que describen las dificultades en el cuidado de enfermería para PVVIH, realizado en diferentes regiones de Brasil (Norte, Nordeste, Sur y Sudeste). Conclusión: Así, los artículos muestran las fallas del sistema público en relación a la atención primaria en las que están vinculadas a la logística de insumos y materiales, limitando la asistencia y perjudicando el acceso a un servicio de calidad.

Palabras clave: Atención primaria de salud; Enfermería; Diagnóstico; VIH.

\section{Introdução}

O vírus da imunodeficiência humana (HIV) afeta milhares de indivíduos no mundo e, em razão disso, tornou-se um problema de saúde pública, pois apresenta consequências em alvejar o sistema imunológico - que se torna responsável por defender o organismo de modo a aumentar a possibilidade das pessoas adquirirem doenças oportunistas (UNAIDS, 2020). No início de 1982 houve surgimento da epidemia no Brasil com uma série de aspectos entre as relações humanas (sexo, gênero, orientação sexual e discriminação) criando, dessa forma, barreiras entre prevenção de nível satisfatório, promoção a saúde e o uso de medicamentos (Greco, 2016).

Segundo o Ministério da Saúde (Brasil, 2013), o vírus do HIV atinge, principalmente, o sistema imune - com objetivo de atingir as células CD4 ou células T, que ajudam a proteger o organismo de patógenos contra infecções, alguns tipos de câncer e/ou pelo desenvolvimento de outras manifestações clínicas graves. O vírus inibe as funções das células e, por isso, as pessoas que convivem com o vírus ficam gradualmente imunodeficientes. De acordo com a Organização Mundial de Saúde (OMS, 2017), os dados revelam que 36,7 milhões de pessoas viviam com HIV até o fim de 2016 e já previa um célere crescimento dos índices: aproximadamente 1,8 milhões de novos casos de infecção pelo vírus em todo o mundo até 2020.

A infecção pelo HIV é diferente da síndrome da imunodeficiência adquirida (AIDS), ou seja, é uma fase mais avançada. Nesse sentido, é válido compreender que uma das falhas para o avanço da síndrome da imunodeficiência adquirida (AIDS) está ligado ao diagnóstico tardio - o que prejudica o início da utilização dos medicamentos antirretrovirais ou devido a fragilidade do sistema imune, podendo aparecer ou não os primeiros sintomas entre 2 a 15 anos de acordo com a reação de cada indivíduo (OMS, 2017; Santos et al., 2012).

Os estágios da infecção pelo HIV se subdivide em três estágios a saber: i) infecção aguda que começa entre 2 e 4 semanas depois após a infecção, com sintomas parecidos ao da gripe é denominada síndrome retroviral aguda (ARS) ou infecção HIV primária; ii) a fase assintomática - Latência Clínica (inatividade ou dormência) - nesse estágio o vírus ainda está ativo, porém há uma replicação em baixos níveis; iii) a fase terciária já é a AIDS (Síndrome da Imunodeficiência Adquirida) quando a infecção danifica, de forma grave, o sistema imunológico e torna-se totalmente vulnerável para as doenças oportunistas (UNAIDS, 2020: Brasil, 2017).

Entre os anos de 2011 e 2012 foi implementado na Atenção Primária de Saúde (APS), pelo Ministério da Saúde (MS), tecnologias que auxiliam no diagnóstico de infecção do HIV/Aids, destacando-se os Testes Rápidos (TR) que aumentou o acesso aos pacientes sobre aconselhamento, informações do teste e, assim, elevar a quantidade de diagnóstico de HIV em todas as regiões do país (Brasil, 2014). O diagnóstico precoce é de suma importância, tanto para os profissionais, quanto para as pessoas que vivem com HIV/Aids, a fim de que inicie os cuidados necessários. Dessa maneira, a Estratégia Saúde da Família (ESF) se torna fundamental nesse processo (Melo et al., 2018).

O Sistema Único de Saúde (SUS) possui assistência integral com uma equipe multiprofissional, tendo um dos maiores 
programas de controle de HIV/Aids; é referência internacional, tanto no tratamento quanto na prevenção (Aguiar \& Alexandre, 2015). Portanto, o profissional de enfermagem se destaca como um dos membros mais importante na consolidação das políticas de saúde, mesmo que o ESF seja composto por equipes de saúde multiprofissionais; o enfermeiro deve continuar atuando como protagonista nas ações de planejamento, organização e operacionalização dos serviços (De Souza et al., 2020).

Diante da problemática surgiu a questão norteadora do estudo: quais as dificuldades enfrentadas pelos enfermeiros na atenção básica de assistência às pessoas que vivem com HIV/AIDS? Há de se considerar que o objetivo do estudo visou analisar, através de uma revisão de literatura, as principais dificuldades na assistência de enfermagem às pessoas que vivem com HIV/AIDS na atenção básica.

A realização do estudo relacionado à temática é essencial para construção do conhecimento, pois o estudo apresentado é de grande relevância, porque permite aos acadêmicos de enfermagem, aos profissionais de saúde e à população obter conhecimento apropriado acerca do atendimento primário na atenção básica para as pessoas que vivem com HIV/AIDS. No estudo foram abordadas informações que buscavam ampliar e fortalecer as discussões acerca da temática.

\section{Metodologia}

Este estudo parte de uma revisão de literatura integrativa do tipo explicativa, de caráter qualitativo. Conforme Yonekura et al. (2014), a revisão integrativa é uma abordagem definida como análise de dados em publicações tanto empíricas como teóricas mostrando e debatendo as ideias dos autores e baseando o trabalho em etapas de construção. Com finalidade de propor resultados sintetizados através de um tema ou pergunta do problema, isto é, formando um corpo de conhecimento. Dentro dessas questões, o revisor/pesquisador pode criar uma revisão integrativa com diversos propósitos, podendo ser dirigido para a descrição e caracterização de teorias ou análises metodológicas.

Destaca-se que esta pesquisa se deu através de seis fases: 1- delimitação do tema; 2- escolha da hipótese ou da questão norteadora estabelecendo uma delimitação para uma busca de dados eficaz; 3- na literatura, separar o conjunto de informações nos estudos; 4- avaliar as informações incluídas; 5- explicar os resultados; Fase 6- mostrar o trabalho onde retrata o processo de integração onde expõe a pesquisa (Melo, Ercole \& Alcoforado, 2014).

Este cenário de estudo avaliou as dificuldades da assistência de enfermagem as pessoas que vivem com HIV/Aids, analisando a qualidade da assistência do profissional de saúde, as falhas do atendimento na atenção básica de saúde de modo a possibilitar acessos reflexivos dos casos para solucionar os problemas. É válido considerar que o levantamento de informações aconteceu no período de agosto de 2020 a maio de 2021, nas bases de dados da Plataforma da Biblioteca Virtual em Saúde (BVS) indexados nas bases de dados, Scientific Eletronic Library Online (SCIELO), Literatuta Latino-Americana e do Caribe em Ciências da Saúde (LILACS), Medical Literature Analysis and Retrieval System Online (MEDLINE). Para isso, foram utilizados como descritores: a Atenção Primária à Saúde; a Enfermagem; o Diagnóstico; o HIV, cruzadas entre si por meio do operador booleano AND.

Utilizou-se, neste contexto, ainda, a Estratégia PICo para a coleta de dados com o fito de encorpar os resultados e discussões. Nesse modelo se considera 4 itens: $\mathrm{P}$ = população ou o paciente ou o problema abordado; $\mathrm{I}=$ a intervenção ou a exposição; Co =contexto e os desfechos ou resultados clínicos de interesse (Outcome). Sendo assim através desse método será ordenado equações de busca para extrair os artigos mais relevantes (Eriksen \& Frandsen, 2018). De acordo com o Quadro 1 mostram os cruzamentos das palavras chave a seguir; 
Quadro 1. Estratégia PICo para buscar dos dados, 2021.

\begin{tabular}{|c|c|c|}
\hline Acrômio & Descritores/palavras-chave & Equação de busca \\
\hline & BVS & BVS \\
\hline $\mathbf{P}$ & $\begin{array}{l}\text { Atenção primaria a saúde AND Enfermagem } \\
\text { AND HIV }\end{array}$ & $\begin{array}{l}\text { ((tw:(atenção primária á saúde)) AND ((tw: } \\
\text { (enfermagem)) AND ((tw: (HIV)) }\end{array}$ \\
\hline $\mathbf{I}$ & Enfermagem AND Diagnostico AND HIV & $\begin{array}{l}((\text { tw:(enfermagem) ) AND ((tw: (diagnóstico )) AND } \\
((\text { tw: (HIV)) }\end{array}$ \\
\hline Co & _ & - \\
\hline Equação geral & \multicolumn{2}{|c|}{$\begin{array}{l}\text { BVS= (tw: ((tw: (atenção primária á saúde)) AND (tw: (enfermagem)) AND (tw: (( HIV))) AND (tw: } \\
((\text { enfermgem)) AND ((tw:(diagnóstico )) AND ((tw: (HIV)) }\end{array}$} \\
\hline
\end{tabular}

Fonte: Autores (2021).

Com base na aplicação das equações gerais de busca apresentadas no quadro, foram identificados, nas bases de dados da Plataforma da Biblioteca Virtual em Saúde (BVS), 532 artigos. Após essa etapa foram incluídos estudos qualitativos e quantitativos, incluindo conteúdos sobre atenção primária à saúde, assistência aos pacientes com HIV, os enfermeiros e a equipe multidisciplinar no cuidado às PVHIV, saúde pública, testes rápidos para HIV, Pessoas que Vivem com HIV, idiomas em português, inglês e espanhol, publicados nos últimos 10 anos no Brasil, com textos completos e disponíveis na íntegra e excluídos sem relevância para a temática e repetidos nas bases de busca.

Sendo assim, foram selecionados 30 artigos nas bases de dados: SCIELO (14), BDENF (06), LILACS (06) e MEDLINE (04), totalizando 30 artigos. Com base nas leituras dos resumos foram excluídos, sem relevância para a temática, artigos repetidos. Em seguida selecionou-se 15 artigos para elaboração dos resultados e discussão do estudo.

Os artigos selecionados foram lidos e analisados de acordo com as seguintes variáveis: autor, ano e o país da publicação, objetivo do estudo, desenho metodológico, caracterização dos participantes, local da pesquisa e os resultados em evidências. Para organizar os dados foi elaborado um formulário (Apêndice) que ajudou no processo de análise dos dados e a busca de conteúdos acerca das dificuldades que os enfermeiros enfrentam na assistência aos pacientes.

No fluxograma elaborou-se um esquema da seleção de estudos com a tematica dificuldades que os enfermeiros enfrentam na assistência as pessoas que vivem com HIV/Aids na atenção básica, de acordo com a analise do estudo cientifico, a seguir: 
Fluxograma 1. Seleção dos estudos para elaboração da pesquisa com HIV/Aids.

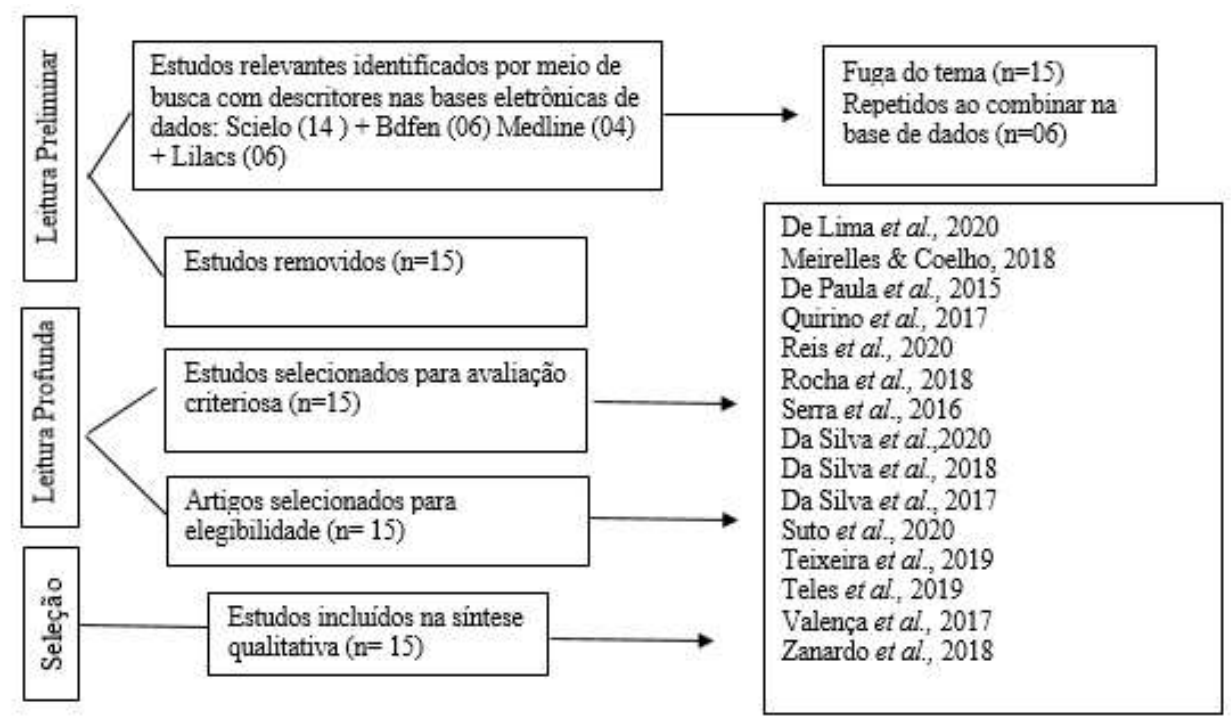

Fonte: Autores (2021)

Após a leitura detalhada do material encontrado, foram analisados os dados do material para obtenção dos elementos importantes dos estudos: resultados e discussão da pesquisa de modo a categorizá-los. Em consequência da análise do material foram dispostos, em um quadro com autor, ano e o país da publicação, objetivo do estudo, desenho metodológico, caracterização dos participantes, local da pesquisa e os resultados em evidências.

\section{Resultados}

\subsection{Caracterização dos estudos incluídos}

De acordo com os resultados obtidos, através dos estudos encontrados, os dados descrevem evidentemente informações importantes que correspondem ao objetivo da pesquisa.

No Quadro 2 abaixo, elaborou-se atráves da caracterização dos artigos cientificos com base nas variáveis abordadas: autor, ano e o país da publicação, objetivo do estudo, desenho metodológico, caracterização dos participantes, local da pesquisa e os resultados em evidências. 
Quadro 2. Perfil dos estudos encontrados de acordo com autor, ano e o país da publicação, objetivo do estudo, desenho metodológico, caracterização dos participantes, local da pesquisa e os resultados em evidências.

\begin{tabular}{|c|c|c|c|c|}
\hline $\begin{array}{c}\text { Autor e } \\
\text { Ano/ } \\
\text { País }\end{array}$ & Objetivo & $\begin{array}{c}\text { Desenho } \\
\text { Metodológico }\end{array}$ & $\begin{array}{l}\text { Caracterização dos } \\
\text { participantes/Local }\end{array}$ & Resultados em evidências \\
\hline $\begin{array}{l}\text { Paula et al., } \\
2015 . \\
\text { Brasil }\end{array}$ & $\begin{array}{l}\text { Compreender a } \\
\text { percepção dos } \\
\text { profissionais sobre a } \\
\text { prática do } \\
\text { aconselhamento em } \\
\text { doenças sexualmente } \\
\text { transmissíveis/HIV na } \\
\text { atenção primária. }\end{array}$ & $\begin{array}{l}\text { Esse trabalho tem } \\
\text { abordagem qualitativa, } \\
\text { sem especificar o tipo } \\
\text { de estudo. } \\
\text { Técnica de coleta de } \\
\text { estudo foi grupo focal. }\end{array}$ & $\begin{array}{l}\text { Este estudo foi feito por } \\
\text { enfermeiros e médicos na } \\
\text { Atenção Primária à Saúde em } \\
\text { Montes Claros, sudeste do } \\
\text { Brasil. }\end{array}$ & $\begin{array}{l}\text { Nos resultados mostram os significados } \\
\text { do aconselhamento e como estava sendo } \\
\text { aplicado pelos profissionais. Na prática } \\
\text { consistiu-se na orientação sobre o uso de } \\
\text { métodos contraceptivos, com destaque } \\
\text { para o preservativo, a vulnerabilidade e a } \\
\text { prevenção de doenças. Pelas falas dos } \\
\text { participantes, foi observado a ausência } \\
\text { de grupos educativos específicos sobre } \\
\text { DST/HIV/AIDS na APS. }\end{array}$ \\
\hline $\begin{array}{l}\text { Serra et al., } \\
2016 . \\
\text { Brasil }\end{array}$ & $\begin{array}{l}\text { Analisar as ações de } \\
\text { prevenção do HIV e } \\
\text { promoção à saúde no } \\
\text { contexto da Aids } \\
\text { desenvolvidas pela } \\
\text { Estratégia Saúde da } \\
\text { Família (ESF), em } \\
\text { João Pessoa-PB. }\end{array}$ & $\begin{array}{l}\text { Estudo descritivo com } \\
\text { abordagem qualitativa. } \\
\text { Técnica de coleta de } \\
\text { estudo utilizou um } \\
\text { roteiro de entrevista } \\
\text { semiestruturado. }\end{array}$ & $\begin{array}{l}\text { Estudo realizado entre } 16 \\
\text { enfermeiros em uma Unidade } \\
\text { Básica de Saúde em João } \\
\text { Pessoa- PB. }\end{array}$ & $\begin{array}{l}\text { Os resultados foram divididos } 4 \text { grupos } \\
\text { em Educação em saúde que, Contextos } \\
\text { para o cuidar, Facilidades e Dificuldades } \\
\text { para ações de prevenção do HIV e } \\
\text { promoção à saúde, onde mostra os } \\
\text { problemas de disponibilidade de } \\
\text { insumos nas UBS, foi apresentado por } \\
\text { um grupo de enfermeiros como } \\
\text { facilitador para o desenvolvimento das } \\
\text { ações preventivas, enquanto para outros } \\
\text { a sua ausência tem dificultado a } \\
\text { consolidação destas. }\end{array}$ \\
\hline $\begin{array}{l}\text { Silva et al., } \\
2017 . \\
\text { Brasil }\end{array}$ & $\begin{array}{l}\text { Analisar a associação } \\
\text { entre os diagnósticos } \\
\text { de enfermagem e } \\
\text { características } \\
\text { sociodemográfi-cas e } \\
\text { clínicas em pessoas } \\
\text { vivendo com Aids. }\end{array}$ & $\begin{array}{l}\text { Trata-se de um estudo } \\
\text { transversal, descritivo, } \\
\text { com abordagem } \\
\text { quantitativa. } \\
\text { Técnica de coleta de } \\
\text { estudo utilizou-se } \\
\text { entrevista e exame } \\
\text { físico durante a coleta } \\
\text { de dados. }\end{array}$ & $\begin{array}{l}\text { Estudo realizado com } 100 \\
\text { pessoas vivendo com Aids, } \\
\text { em Hospital de referência em } \\
\text { atendimento de doenças } \\
\text { infecciosa e parasitarias com } \\
\text { centro de testagem e } \\
\text { ambulatório em uma cidade } \\
\text { do Nordeste. }\end{array}$ & $\begin{array}{l}\text { Nos resultados destaca-se que as pessoas } \\
\text { vivendo com Aids, em sua maior parte, } \\
\text { era do sexo masculino, com a faixa } \\
\text { etária entre } 30 \text { e } 39 \text { anos, não possuía } \\
\text { companheiro e alguns tinham ensino } \\
\text { fundamental incompleto. Identificaram- } \\
\text { se } 56 \text { diagnósticos de enfermagem, } \\
\text { prevalecido mais de } 50 \% \text { das pessoas } \\
\text { vivendo com Aids. }\end{array}$ \\
\hline $\begin{array}{l}\text { Valença, } \\
\text { Silva \& } \\
\text { Silva, } 2017 . \\
\text { Brasil }\end{array}$ & $\begin{array}{l}\text { Analisar a } \\
\text { implementação do } \\
\text { teste rápido anti-HIV } \\
\text { na Estratégia Saúde } \\
\text { da Família (ESF) na } \\
\text { perspectiva de } \\
\text { enfermeiros. }\end{array}$ & $\begin{array}{l}\text { Trata-se de um estudo } \\
\text { descritivo e } \\
\text { exploratório, com } \\
\text { abordagem qualitativa. } \\
\text { Técnica de coleta de } \\
\text { dados por meio de } \\
\text { roteiro de entrevista } \\
\text { semiestruturada. }\end{array}$ & $\begin{array}{l}\text { Os participantes do estudo } \\
\text { foram os enfermeiros da ESF } \\
\text { no estado da Paraíba. }\end{array}$ & $\begin{array}{l}\text { Os resultados foram divididos em quatro } \\
\text { categorias, onde as falas dos enfermeiros } \\
\text { apontavam problemas na infraestrutura } \\
\text { básica, insumos, dificuldade de } \\
\text { implementação do TR anti-HIV na ESF. } \\
\text { Os enfermeiros receberam capacitação } \\
\text { porém, os aspectos vão além da técnica, } \\
\text { como o preparo do profissional no } \\
\text { aconselhamento, dificuldades no } \\
\text { atendimentos das demandas por causa da } \\
\text { quantidade limitada de kits e a } \\
\text { sobrecarga de atividades. }\end{array}$ \\
\hline $\begin{array}{l}\text { Quirino et } \\
\text { al., } 2018 . \\
\text { Brasil }\end{array}$ & $\begin{array}{l}\text { Conhecer a percepção } \\
\text { de profissionais de } \\
\text { saúde executores de } \\
\text { teste rápido em } \\
\text { Unidades Básicas de } \\
\text { Saúde (UBS). }\end{array}$ & $\begin{array}{l}\text { Trata-se de um estudo } \\
\text { descritivor com } \\
\text { abordagem qualitativa. } \\
\text { Técnica de coleta de } \\
\text { dados foi por meio de } \\
\text { entrevista. }\end{array}$ & $\begin{array}{l}\text { Os participantes foram } \\
\text { enfermeiros capacitados para } \\
\text { realização do teste rápido na } \\
\text { UBS em } \quad \text { Recife, } \\
\text { Pernambuco. }\end{array}$ & $\begin{array}{l}\text { Nos resultados mostraram asfragilidades } \\
\text { para realização dos testes rápidos } \\
\text { relacionadas à logística da entrega dos } \\
\text { insumos e materiais, estrutura física para } \\
\text { realização dos testes e aconselhamento } \\
\text { pré e pós-teste precisa melhorar a } \\
\text { capacitação profissional e na execução } \\
\text { de atividades em educação permanente. }\end{array}$ \\
\hline $\begin{array}{l}\text { Meirelles \& } \\
\text { Coelho, }\end{array}$ & $\begin{array}{l}\text { Compreender o } \\
\text { compartilhamento do } \\
\text { cuidado à pessoa }\end{array}$ & $\begin{array}{l}\text { Está pesquisa tem a } \\
\text { abordagem qualitativa } \\
\text { com aporte } \\
\text { metodológicor da } \\
\text { Teoria Funda-mentada } \\
\end{array}$ & $\begin{array}{l}\text { Os participantes foram } 19 \\
\text { profissionais da Rede de } \\
\text { Atenção à Saúde da capital } \\
\text { Catarinense. }\end{array}$ & $\begin{array}{l}\text { Neste estudo os profissionais dos } \\
\text { diferentes grupos amostrais relataram } \\
\text { que, para poder incentivar tratamento } \\
\text { antirretroviral a adesão, acesso as } \\
\text { consultas aos adultos jovens com }\end{array}$ \\
\hline
\end{tabular}




\begin{tabular}{|c|c|c|c|c|}
\hline $\begin{array}{l}2018 . \\
\text { Brasil }\end{array}$ & $\begin{array}{l}\text { vivendo com HIV/ } \\
\text { Aids, com destaque } \\
\text { ao adulto jovem e à } \\
\text { estruturação de linha } \\
\text { de cuidado na capital } \\
\text { catarinense. }\end{array}$ & \begin{tabular}{l} 
nos Dados (TFD). \\
Técnica de coleta de \\
dados utilizaram \\
caracterização \\
sujeitos dos \\
entrevista em \\
\multicolumn{2}{l}{ semiestruturada. }
\end{tabular} & & $\begin{array}{l}\text { HIV/Aids, reforçar a capacitação dos } \\
\text { profissionais das UBS para ajudar na } \\
\text { ampliação da realização do teste rápido } \\
\text { para diagnóstico de HIV. }\end{array}$ \\
\hline $\begin{array}{l}\text { Rocha et al., } \\
2018 . \\
\text { Brasil }\end{array}$ & $\begin{array}{lr}\text { Analisar como } & \text { o } \\
\text { estigma e } & \text { a } \\
\text { discriminação estão } \\
\text { presentes no cotidiano } \\
\text { de usuários } & \text { e } \\
\text { profissionais } & \text { no } \\
\text { contexto } & \text { de } \\
\text { implementação } & \text { do } \\
\text { teste rápido para } \\
\text { HIV/Aids na Atenção } \\
\text { Básica. }\end{array}$ & $\begin{array}{l}\text { Trata-se de um estudo } \\
\text { qualitativo, } \\
\text { exploratório } \\
\text { descritivo. } \\
\text { A técnica de coleta de } \\
\text { dados, utilizaram-se } \\
\text { entrevistas } \\
\text { semiestruturadas. }\end{array}$ & $\begin{array}{l}\text { Os participantes foram } 64 \\
\text { pessoas, sendo } 34 \text { usuários, } \\
19 \text { enfermeiros, 03 técnicos } \\
\text { de enfermagem, 02 agentes } \\
\text { comunitários de saúde, } \\
02 \text { médicos ginecologistas, } \\
01 \text { médico da família, 02 } \\
\text { cirurgiões-dentistas e 01 } \\
\text { nutricionista em Porto } \\
\text { Alegre, Rio Grande do Sul. }\end{array}$ & $\begin{array}{l}\text { Neste estudo elaborou-se uma síntese } \\
\text { interpretativa em que as falas dos } \\
\text { participantes dialogam com o cenário do } \\
\text { estigma do HIV/AIDS e o contexto do } \\
\text { teste rápido na AB. o estigma associado } \\
\text { ao HIV se faz presente nas diferentes } \\
\text { falas dos entrevistados. De forma geral, } \\
\text { profissionais e usuários percebem } \\
\text { estigma e discriminação na comunidade } \\
\text { e nos serviços de saúde, sem uma } \\
\text { implicação crítica sobre sua participação } \\
\text { nesse processo. }\end{array}$ \\
\hline $\begin{array}{l}\text { Silva, Silva } \\
\text { \& Ferreira, } \\
2018 . \\
\text { Brasil }\end{array}$ & $\begin{array}{l}\text { Analisar a percepção } \\
\text { de profissionais de } \\
\text { saúde sobre práticas } \\
\text { de aconselhamento } \\
\text { em um Centro de } \\
\text { Testagem e } \\
\text { Aconselhamento em } \\
\text { Infecções } \\
\text { Sexualmente } \\
\text { Transmissíveis } \\
\text { (IST) e Aids em } \\
\text { Maceió, Alagoas. }\end{array}$ & $\begin{array}{l}\text { Trata-se de uma } \\
\text { pesquisa qualitativa, } \\
\text { com referencial teórico } \\
\text { das Práticas } \\
\text { Discursivas. } \\
\text { Técnica de coleta de } \\
\text { dados foi utilizada a } \\
\text { roda de conversa. }\end{array}$ & $\begin{array}{l}\text { Os participantes foram } 06 \\
\text { aconselhadores } 03 \text { psicólogos } \\
\text { e } 03 \text { assistentes sociais, foi } \\
\text { realizada em um CTA em } \\
\text { Alagoas. }\end{array}$ & $\begin{array}{l}\text { Nos resultados mostram, que os } \\
\text { participantes relembraram que no início } \\
\text { das atividades na unidade especializada } \\
\text { em HIV/Aids o preconceito era expresso } \\
\text { pelos Trabalhadores nas relações com } \\
\text { outros profissionais do mesmo } \\
\text { estabelecimento de saúde. No } \\
\text { acolhimento, há uma forte preocupação } \\
\text { com a qualidade, desde a recepção do } \\
\text { usuário, passando pela responsabilização } \\
\text { do profissional com o usuário, pela } \\
\text { integralidade do cuidado, a escuta a suas } \\
\text { demandas e a oferta de espaços com } \\
\text { infraestrutura. }\end{array}$ \\
\hline $\begin{array}{l}\text { Zanardo et } \\
\text { al., } 2018 . \\
\text { Brasil }\end{array}$ & $\begin{array}{l}\text { Conhecer e analisar } \\
\text { como o } \\
\text { aconselhamento em } \\
\text { HIV/Aids vem sendo } \\
\text { desenvolvido na } \\
\text { descentralização do } \\
\text { teste rápido de HIV e } \\
\text { outras Infecções } \\
\text { Sexualmente } \\
\text { Transmissíveis (IST) } \\
\text { para a atenção básica. }\end{array}$ & $\begin{array}{l}\text { Trata-se de um estudo } \\
\text { com abordagem } \\
\text { qualitativa, de caráter } \\
\text { exploratório, } \\
\text { descritivo e analítico. } \\
\text { Possui técnica de } \\
\text { coleta de dados por } \\
\text { entrevista. }\end{array}$ & $\begin{array}{l}\text { A pesquisa foi realizada na } \\
\text { atenção básica de Porto } \\
\text { Alegre, os } 22 \text { participantes, } \\
19 \text { enfermeiros, } 01 \\
\text { nutricionista, 01 médico } \\
\text { ginecologista e um dentista } \\
\text { em Porto alegre- RS. }\end{array}$ & $\begin{array}{l}\text { Os resultados se dividem em cinco } \\
\text { categorias em dois eixos temáticos o } 1 \\
\text { eixo; Descentralização da testagem na } \\
\text { atenção básica que contempla duas } \\
\text { categorias: a) processo de implantação } \\
\text { do teste rápido; b) dinâmica do teste } \\
\text { rápido e aconselhamento. O segundo } \\
\text { eixo "Aconselhamento - elementos e } \\
\text { desafios apresenta } 03 \text { categorias: aspecto } \\
\text { informativo e educativo; práticas sexuais } \\
\text { e gestão de riscos; suporte emocional. }\end{array}$ \\
\hline $\begin{array}{l}\text { Teixeira et } \\
\text { al., } 2019 . \\
\text { Brasil }\end{array}$ & $\begin{array}{l}\text { Construir com os } \\
\text { profissionais de saúde } \\
\text { uma tecnologia } \\
\text { educacional para } \\
\text { mediar o processo de } \\
\text { educação em saúde no } \\
\text { contexto HIV/Aids. }\end{array}$ & $\begin{array}{l}\begin{array}{l}\text { Trata-se de uma } \\
\text { pesquisa }\end{array} \\
\text { abordagem qualitativa, } \\
\text { com interface com a } \\
\text { pesquisa-ação. A } \\
\text { técnica de coleta de } \\
\text { dados por grupo focal. }\end{array}$ & $\begin{array}{l}\text { Esse estudo foi realizado } \\
\text { com } 08 \text { profissionais das } \\
\text { áreas de Enfermagem, } \\
\text { Biomedicina, Serviço Social, } \\
\text { Psicologia e Bioquímica em } \\
\text { Belém-PA. }\end{array}$ & $\begin{array}{l}\text { Os resultados foram de acordo com as } \\
\text { falas dos participantes para construir um } \\
\text { material educativo com as principais } \\
\text { informações e duvidas para os usuários, } \\
\text { família e profissionais de saúde, tendo } \\
\text { foco nos profissionais de enfermagem } \\
\text { em uma unidade de referência } \\
\text { especializada no atendimento a pessoas } \\
\text { com HIV/AIDS. }\end{array}$ \\
\hline $\begin{array}{l}\text { Teles et al., } \\
2019 . \\
\text { Brasil }\end{array}$ & $\begin{array}{l}\text { Apreender o conteúdo } \\
\text { e a estrutura das } \\
\text { representações sociais } \\
\text { de profissionais de } \\
\text { saúde sobre o teste } \\
\text { rápido para detecção } \\
\text { de infecções } \\
\text { sexualmente } \\
\text { transmissíveis em um } \\
\text { município baiano. }\end{array}$ & $\begin{array}{l}\text { Trata-se de uma } \\
\text { pesquisa } r \text { com } \\
\text { abordagem qualitativa } \\
\text { com o tipo de estudo } \\
\text { descritivo ro } \\
\text { exploratório. Possui } \\
\text { técnica de coleta de } \\
\text { dados por roteiro de } \\
\text { questões e entrevista. }\end{array}$ & $\begin{array}{l}\text { Neste estudo foi aplicado } \\
\text { entre os profissionais de } \\
\text { nível universitário } \\
\text { (enfermeiras, médicos, } \\
\text { farmacêuticos, odontólogos e } \\
\text { assistentes sociais), UBS do } \\
\text { município de Senhor do } \\
\text { Bonfim-Bahia }\end{array}$ & $\begin{array}{l}\text { Nos resultados mostram que as } \\
\text { atividades educativas, } \\
\text { consulta/atendimento, oferta de exame e } \\
\text { distribuição de preservativos são ações } \\
\text { realizadas por cerca de } 50 \% \text { dos } \\
\text { participantes do estudo; e o teste rápido } \\
\text { por } 32 \% \text { Os testes rápidos são } \\
\text { realizadas no máximo em } 30 \text { minutos, } \\
\text { necessita de treinamento dos } \\
\text { profissionais, sendo recomendados para } \\
\text { testagens presenciais. Os dados revelam }\end{array}$ \\
\hline
\end{tabular}




\begin{tabular}{|c|c|c|c|c|}
\hline & & & & $\begin{array}{l}\text { que, há avanços na área da saúde, no } \\
\text { tocante ao manejo do teste rápido, ainda } \\
\text { persiste o medo. }\end{array}$ \\
\hline $\begin{array}{l}\text { Lima et al., } \\
2020 . \\
\text { Brasil }\end{array}$ & $\begin{array}{l}\text { Para entender as } \\
\text { necessidades de ajuda } \\
\text { de homens que fazem } \\
\text { sexo com homens e } \\
\text { vivem com o HIV à } \\
\text { luz de uma teoria } \\
\text { prescritiva. }\end{array}$ & $\begin{array}{l}\text { Trata-se de estudo } \\
\text { descritivo, com uma } \\
\text { abordagem qualitativa. } \\
\text { Técnica de coleta de } \\
\text { dados ocorreu por } \\
\text { meio de entrevistas } \\
\text { individuais } \\
\text { formulário } \\
\text { semiestruturado. }\end{array}$ & $\begin{array}{l}\text { Foram } 49 \text { participantes do } \\
\text { sexo masculino com } \\
\text { diagnóstico com HIV. } \\
\text { Foi desenvolvido durante os } \\
\text { Serviço Ambulatorial } \\
\text { Especializado (SAE) de uma } \\
\text { capital no Nordeste do } \\
\text { Brasil. }\end{array}$ & $\begin{array}{l}\text { Os resultados mostram informações } \\
\text { relacionados às necessidades de ajuda } \\
\text { dos participantes do estudo e ao papel do } \\
\text { enfermeiro. Com descrição do apoio, } \\
\text { acolhimento, suporte psicossocial e } \\
\text { familiar. O desejo de receber auxílio foi } \\
\text { relacionado à aceitação e ao } \\
\text { esquecimento do diagnóstico. Os } \\
\text { problemas enfrentados aludiram à } \\
\text { aceitação do diagnóstico, ao medo e ao } \\
\text { preconceito. }\end{array}$ \\
\hline $\begin{array}{l}\text { Reis et al., } \\
2020 . \\
\text { Brasil }\end{array}$ & $\begin{array}{l}\text { Analisar se existe } \\
\text { diferenças entres as } \\
\text { características } \\
\text { sociodemográficos, } \\
\text { clínicos e afetivos- } \\
\text { sexuais nas diferentes } \\
\text { parcerias sexuais } \\
\text { entre pessoas vivendo } \\
\text { com HIV/aids. }\end{array}$ & $\begin{array}{l}\text { Trata-se de um estudo } \\
\text { de caráter transversal. } \\
\text { A técnica de coleta de } \\
\text { dados } \\
\text { entrevistas } \\
\begin{array}{l}\text { questionário } \\
\text { construído }\end{array} \\
\text { estudo. }\end{array}$ & $\begin{array}{l}\text { Estudo desenvolvido com } \\
173 \text { participantes/usuários } \\
\text { com HIV, realizado em um } \\
\text { serviço de assistência } \\
\text { especializado (SAE), Centro } \\
\text { Integrado de Saúde no } \\
\text { Estado do Piauí, região do } \\
\text { nordeste do Brasil. }\end{array}$ & $\begin{array}{l}\text { Nos resultados os dados foram } \\
\text { levantados através dos pacientes } \\
\text { cadastrados na unidade. Às variáveis } \\
\text { sociodemográficas e clínicas e sua } \\
\text { associação com a sorologia do parceiro, } \\
\text { identificou-se que as parcerias sexuais } \\
\text { sorodiscordantes em sua maioria eram } \\
\text { do sexo masculino, adultos jovens com } \\
\text { faixa etária entre } 18 \text { a } 39 \text { anos, as } \\
\text { informações como grau de escolaridade, } \\
\text { cor, sexo, orientação sexual, idade, } \\
\text { estado civil foram incluídas para auxiliar } \\
\text { nos resultados. }\end{array}$ \\
\hline $\begin{array}{l}\text { Silva et al., } \\
2020 . \\
\text { Brasil }\end{array}$ & $\begin{array}{l}\text { Conhecer as } \\
\text { percepções de pessoas } \\
\text { que vivem com HIV } \\
\text { sobre o cuidado que } \\
\text { lhes é oferecido na } \\
\text { Atenção Básica. }\end{array}$ & $\begin{array}{l}\text { Pesquisa descritiva e } \\
\text { exploratória, com } \\
\text { abordagem qualitativa. } \\
\text { Técnica de coleta de } \\
\text { dados utilizaram } \\
\text { entrevista }\end{array}$ & $\begin{array}{l}\text { Estudo desenvolvido no SAE } \\
\text { em HIV/Aids de um } \\
\text { município da Zona da Mata } \\
\text { Mineira. }\end{array}$ & $\begin{array}{l}\text { No estudo } 16 \text { pessoas, onde a partir das } \\
\text { falas, emergiram três categorias: } \\
\text { Atenção Básica: um cenário } \\
\text { subestimado para prestação de cuidados } \\
\text { em HIV; Medo de ruptura do sigilo: } \\
\text { obstáculo para buscar cuidados na } \\
\text { Atenção Básica; Perspectiva controversa } \\
\text { de cuidado integral sem a participação } \\
\text { da Atenção Básica. Verificou-se que os } \\
\text { pacientes consideraram como um bom } \\
\text { serviço, porém não buscavam cuidados } \\
\text { relacionados ao HIV nesse cenário, } \\
\text { subestimando suas potencialidades. }\end{array}$ \\
\hline $\begin{array}{l}\text { Suto et al., } \\
2020 . \\
\text { Brasil }\end{array}$ & $\begin{array}{l}\text { Analisar as } \\
\text { representações sociais } \\
\text { de mulheres com } \\
\text { diagnóstico de HIV } \\
\text { sobre sua sexualidade } \\
\text { considerando as } \\
\text { características } \\
\text { geracionais. }\end{array}$ & 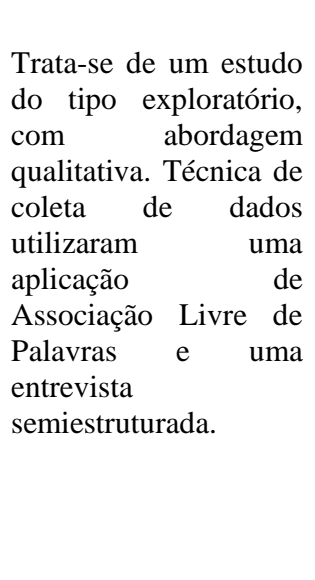 & $\begin{array}{l}\text { A pesquisa foi desenvolvida } \\
\text { em uma população do sexo } \\
\text { feminino em uma unidade de } \\
\text { saúde da rede municipal, } \\
\text { única em funcionamento na } \\
\text { condição de Serviço de } \\
\text { Atenção } \\
\text { (SAE), em Feira de Santana- } \\
\text { BA. }\end{array}$ & $\begin{array}{l}\text { Nos resultados mostram que as } \\
\text { características sociais e relativas aos } \\
\text { grupos geracionais, onde delimitou-se de } \\
\text { acordo com a faixa etária, nível de } \\
\text { ensino, tempo de diagnóstico, situação } \\
\text { econômica, condição marital e } \\
\text { companheiro, sendo pessoas que vivem } \\
\text { com o vírus ou não. As falas das } \\
\text { participantes carregam questões } \\
\text { culturais, representações negativas sobre } \\
\text { o estilo de vida e a sexualidade. } \\
\text { Apontam também elementos afetivos, } \\
\text { psíquicos e atitudinais, como medo, } \\
\text { vergonha, necessidade de esconder o } \\
\text { diagnóstico e mudanças no no } \\
\text { relacionamento com o companheiro. }\end{array}$ \\
\hline
\end{tabular}

Fonte: Autores (2021).

O Quadro 2 apresenta os artigos selecionados para construção do estudo; para efeito de organização, seguiu-se este parâmetro: os autores, ano e o país da publicação, objetivo do estudo, desenho metodológico, caracterização dos participantes, local da pesquisa e os resultados em evidências, para auxiliar no desenvolvimento da discussão. Conforme os dados dos artigos foram determinados variáveis importantes para análise dos trabalhos científicos. 
$\mathrm{Na}$ apuração das informações dos 15 artigos para realização do estudo cientifico, após aplicação dos critérios de inclusão e exclusão, examinou-se que nos anos de 2018 a 2020 teve um percentual de 73,33\% de periódicos, se comparado aos anos de 2015 a 2017 com percentual de $26,67 \%$. Na modalidade de estudo, foram selecionadas as pesquisas de campo e as áreas de estudo em destaque nos artigos selecionados foram de regiões no Brasil de equipes de enfermagem e multidisciplinar.

Nas características dos artigos que estão descritas no Quadro 02, os estudos foram publicados em diferentes regiões do Brasil: Sudeste ( $n=02 ; 13,33 \%)$, Nordeste ( $n=09 ; 60 \%)$, Norte $(n=01 ; 6,67 \%)$, Sul ( $n=03 ; 20 \%)$. Os artigos incluídos foram estudos qualitativos descritivos $(\mathrm{n}=2)$, qualitativo com interface com a pesquisa-ação $(\mathrm{n}=1)$, qualitativo descritivo-exploratório $(\mathrm{n}=3)$, qualitativo exploratório, descritivo e analítico $(\mathrm{n}=1)$, quantitativa transversal $(\mathrm{n}=2)$, qualitativo exploratório $(\mathrm{n}=2)$, qualitativo fenomenológico $(n=1)$ e estudos qualitativos não especificaram $(n=3)$. A coleta dos dados foi realizada por entrevista semiestruturado $(n=12)$, grupo focal $(n=2)$, roteiro $(n=3)$, exame físico $(n=1)$, roda de conversa $(n=1)$, formulário $(\mathrm{n}=1)$ e questionário $(\mathrm{n}=1)$.

\subsection{Dificuldades na assistência as pessoas que vivem com HIV/Aids}

A figura 1 abaixo está relacionada com os resultados dos estudos, onde foi criando três categorias para auxiliar a construção da discussão, apontando as principais informações que correspondem a questão de pesquisa: Quais as dificuldades que os enfermeiros enfrentam na atenção básica na assistência as pessoas que vivem com HIV/AIDS?

Figura 1. A formação das categorias e subcategorias selecionadas através das informações dos artigos, de acordo com a temática abordada.

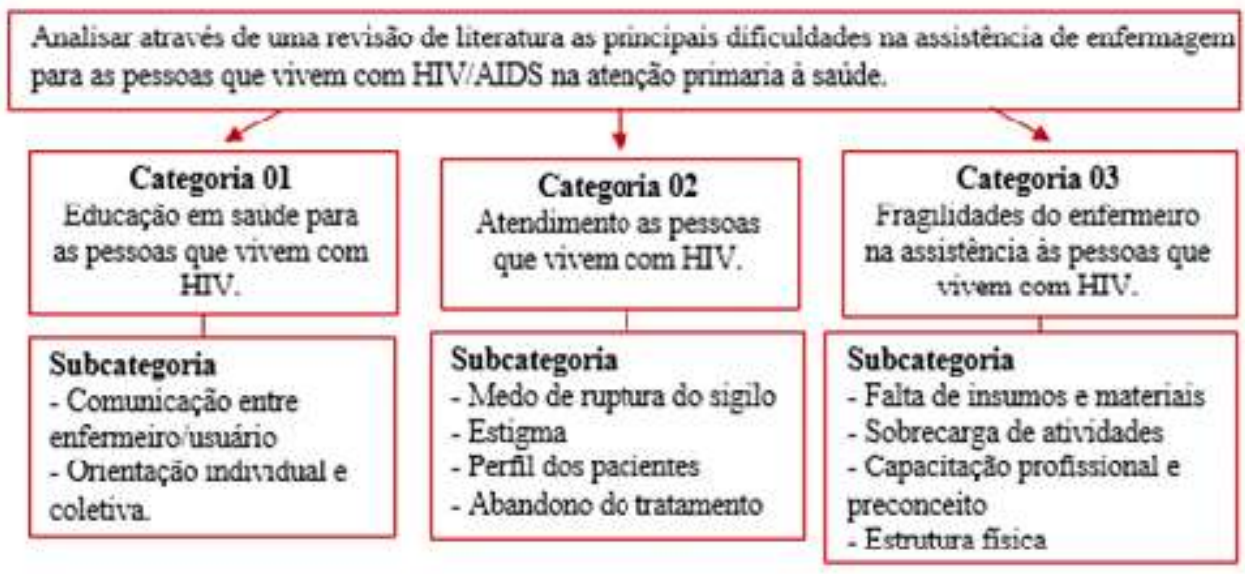

Fonte: Biblioteca Virtual da Saúde (2021).

\subsubsection{Educação em saúde para as pessoas que vivem com HIV}

A educação em saúde para as pessoas que vivem com HIV caracteriza-se como um instrumento, através da comunicação, para auxiliar a assistência de enfermagem que promove o acolhimento, aconselhamento, esclarece dúvidas sobre a utilização de preservativos em que se mostram evidências de que, na Estratégia e Saúde da Família, deve haver uma intensificada ação de uso, pois, assim se promoverá ações de melhoria para qualidade de vida dessa população assistida pelo enfermeiro (Serra et al., 2016; Teles et al., 2019). O profissional deve estabelecer um vínculo com os pacientes para proporcionar um atendimento adequado, acompanhar o tratamento dos usuários que tem dúvidas sobre a terapia antirretroviral associando-se juntamente com uso do preservativo e a pratica do sexo seguro (De Paula et al., 2015).

Em se tratando de educação em saúde pode haver, os múltiplos estudos indicam uma subdivisão para melhor compreensão do tema, podendo ser individual - que se dá através da consulta de enfermagem e visitas domiciliares em um 
espaço privativo através da comunicação e relação enfermeiro/usuário propondo orientações (Serra et al., 2016); e também coletivo- em que se busca promover a educação em saúde - como uma atividade realizada pelos enfermeiros da UBS - tendo por função a interação do profissional com o usuário através das demandas utilizando a sala de espera da AB (Zanardo et al., 2018).

Os profissionais de saúde precisam planejar ações educacionais na AB para dar dicas de como ter uma qualidade de vida satisfatória para pessoas que vivem com HIV/AIDS, formando um conjunto de informações claras e objetivas reunidas em materiais educativos, tanto para facilitar o entendimento dos usuários, como para o próprio trabalho dos profissionais (Texeira et al., 2019). O profissional tem livre acesso para estabelecer uma distribuição, durantes as ações educativas, como panfletos, folders, cartazes com informações importantes que o paciente possa absorver, nas palestras, rodas de conversas e campanhas estabelecidas pelas políticas públicas de saúde. (Zanardo et al., 2018).

\subsubsection{Atendimento às pessoas que vivem com HIV}

Essa categoria foi constituída através da percepção do enfermeiro no atendimento da atenção básica, onde é importante para avaliar as dificuldades e melhorar o seu planejamento de atividades, pois existem falhas no sistema público de saúde para uma assistência de qualidade, mostrando então, as dificuldades para realização do teste rápido de HIV para a população e controle desta Infecção Sexualmente Transmissível (Quirino et al., 2017).

No atendimento do enfermeiro aos homens, que comparecem com menos frequência na $\mathrm{AB}$, onde possuem vida sexual ativa com parceiros fixos ou eventuais, o profissional torna-se uma chave importante durante a aceitação do diagnostico, a orientação no uso de preservativos, tratamento antirretroviral, mudança de estilo de vida (De Lima et al., 2020). Na assistência à saúde, as mulheres mostram-se mais frequente nas consultas da $\mathrm{AB}$; os profissionais de saúde relatam que, geralmente, a maioria das mulheres diagnosticadas com HIV possui parceiro único. Os dados mostram elementos subjetivos para esclarecer a proposta de discussão: sentimentos, como o medo, permeia esse momento na vida da diagnosticada- em muitos casos, elas preferem esconder o resultado da família e do parceiro (Suto et al., 2020).

Conforme os dados encontrados, há diversos fatores que podem impactar o diagnóstico e o atendimento de PVHA na atenção básica (Quirino et al., 2017). As questões mostram evidências relacionadas ao estigma da população com a doença, abandono ao tratamento da terapia antirretroviral, relatam dificuldades no acesso ao serviço de saúde, mesmo com os avanços nas informações e manejo de PVHA, tendo uma necessidade de instrumentos e materiais no apoio didático sobre a infecção por HIV/Aids (Valença et al., 2017; Da Silva et al., 2017).

Percebe-se, então, que os profissionais consideraram a APS um local apropriado, para orientar aos pacientes durante as consultas de enfermagem e repassar informações adequadas, diminuindo os riscos de adquirir o HIV, pois o vínculo entre profissional-usuário ajuda na assistência antes e após o diagnóstico e durante o tratamento (De Paula et al., 2015). A gestão pública perante a epidemia do HIV/AIDS vem traçando estratégias para diminuir as populações suscetíveis a IST, pois os profissionais reconhecem que o risco de infecção está ligado às práticas sexuais sem uso de preservativos (Rocha et al., 2018).

\subsubsection{Fragilidades do enfermeiro na assistência às pessoas que vivem com HIV}

Essa categoria foi constituída a partir dos fatores que causam as fragilidades na assistência de enfermagem no serviço de saúde pública, procurando-se soluções para melhorar o atendimento na $\mathrm{AB}$, onde o gerenciamento do risco da transmissão sexual do HIV entre as parcerias sexuais e a escolha de uma estratégia de prevenção são influenciadas particularmente por posições econômica, social, política e culturalmente desfavorecidas (Reis et al., 2020; Zanardo et al., 2018).

$\mathrm{Na}$ realização do acompanhamento dos pacientes, os profissionais da atenção primária à saúde desenvolvem seu papel, tendo em busca a meta 90-90-90, 90\% casos que sabem do diagnostico, $90 \%$ casos em tratamento com a terapia 
antirretroviral, 90\% casos de carga viral indetectável (Meirelles \& Coelho, 2018). No processo do aconselhamento em HIV/Aids implica lidar diretamente com situações variadas e, muitas vezes, distantes de nossos valores e estilos de vida (Da Silva et al., 2018).

Diante das barreiras que os enfermeiros enfrentam foram encontradas as questões de implementação dos testes rápidos interligados diretamente à logística da entrega dos insumos e materiais, estrutura física para realização dos testes e aconselhamento pré e pós-teste, capacitação profissional, dificuldades para realização de atividades educativas relacionadas à necessidade de sistematização das atividades de educação permanente (Da Silva et al., 2020).

Nos estudos observa-se que o tempo insuficiente da capacitação implica diretamente na abordagem do paciente submetido ao teste gerando uma fragilidade (Quirino et al., 2017). Os aspectos de atendimento ao paciente são além de técnicas, o profissional necessita de um preparo no aconselhamento e especialmente voltado para um paciente com um resultado positivo (Texeira et al., 2019). Destacam-se ainda a participação marcante de enfermeiros na capacitação e a ausência de outras categorias profissionais, mesmo a testagem se caracterizando como um procedimento multiprofissional (Valença et al., 2017).

\section{Discussões}

Os resultados dos artigos científicos analisados nessa revisão expõem as dificuldades que a assistência de enfermagem enfrentam na atenção básica às pessoas que vivem com HIV/Aids e as falhas do sistema público de saúde.

De acordo com Serra et al. (2016), o atendimento do enfermeiro às PVHIV contêm algumas dificuldades na implementação de planejamentos de atividades, capacitação profissional e conhecimento apropriado sobre infecção pelo HIV para realizar educação em saúde, considerando-se então um instrumento importante, durante as consultas de enfermagem. Conforme Teixeira et al. (2019), o profissional de saúde deve buscar as principais dúvidas manifestadas pelas pessoas que vivem com HIV/AIDS, para compreender e planejar ações na comunicação clara de informações durantes os atendimentos, alguns materiais didáticos como folders, cartazes, panfletos com os principais questionamentos tanto para o usuário como para a família.

Estudo realizado por De Paula et al. (2015), afirma que o profissional de saúde deve analisar o nível de conhecimento do cliente/paciente sobre a infecção por HIV, para ampliar a comunicação e vínculo entre profissionais e usuários em relação aos questionamentos mais comuns durante os atendimentos. Para Quirino et al. (2017), nas unidades básicas de saúde precisam de investimentos a fim de que haja a realização de testes rápidos para HIV, auxiliando na ampliação dos diagnósticos e início do tratamento antirretroviral, visto que alguns estudos demonstram que a aceitação do teste sorológico para HIV na Atenção Primária cresceu de forma positiva.

Conforme o estudo de Zanardo et al. (2018), os profissionais afirmam que há uma sobrecarga também de trabalho nas UBS, sendo necessário desenvolver programas e políticas de saúde - essa excedência dificulta o acompanhamento dos pacientes que vivem com HIV. De acordo com o Serra et al. (2016), o enfermeiro, durante o tratamento, deve orientar sobre terapia antirretroviral, aconselhando também sobre o uso de métodos contraceptivos, com destaque para o preservativo, a vulnerabilidade e a prevenção de IST's.

Segundo Quirino et al. (2017), a percepção do enfermeiro no atendimento da atenção básica coloca em destaque vários obstáculos a serem vencidos, dentre eles o medo e o preconceito em relação ao diagnóstico positivo para HIV/Aids, pontuando alguns questionamentos relacionados à rejeição as PVHIV no acompanhamento do tratamento na atenção primária. Segundo o estudo realizado por De Lima et al. (2020), a presença do enfermeiro está sendo positiva, com um desempenho nas atividades aos cuidados às PVHIV, mostrando que as práticas de Enfermagem geram um apoio inicial no vinculo estabelecido do profissional em relação a empatia e confiança para paciente. 
Diante da assistência às pessoas que vivem com HIV, as mulheres demonstram ser o público que mais frequentam a unidade básica de saúde nas consultas para realizar o acompanhamento da saúde; os profissionais destacam que há um sentimento de medo do julgamento ao revelar aos seus parceiros sobre o diagnóstico positivo para HIV, pois, notavelmente, a fidelidade e a confiança do casal são postas à prova, ou seja, o perfil feminino pode assumir uma postura de vítima e/ou culpada (Suto et al., 2020). Conforme De Lima et al. (2020), os homens têm o maior índice de diagnósticos por HIV no atendimento na (APS). Dentro deste contexto, o autor destaca que esse grupo masculino tende a comparecer com menos frequência na unidade e complementa informando que isso configura um problema ligado às questões de poder estabelecidas nas relações socioculturais. Infere-se, assim, que o homem é uma figura resistente, sobretudo nos primeiros instantes do diagnóstico. Nesse entremeio, a figura do enfermeiro torna-se basilar no processo, pois, por meio de um atendimento humanizado, pode implementar, na sua prática, um diálogo claro, a fim de explicar os benéficos do início e continuidade do tratamento.

Neste estudo os enfermeiros que participaram da entrevista afirmam que a falta de insumos de testagem prejudica, de forma significativa, o rastreamento das pessoas que vivem com HIV, em quantidade limitada dificultando o acesso das populações ao exame (Valença et al., 2017). Para Da Silva et al. (2017), a equipe de enfermagem precisa de materiais e insumos para ter o controle da infecção, realizando o acompanhamento adequado dos pacientes antes e durante o diagnóstico, estando a frente do uso da TARV evitando abandono e futuras infecções oportunistas.

Conforme De Paula et al. (2018), na atenção primária o profissional de enfermagem realiza um atendimento ao cliente, permitindo acompanhar ao longo do tempo o histórico da infecção pelo HIV, podendo manter os cuidados e proporcionar orientações de qualidade de vida. Para Rocha et al. (2018), a gestão em saúde é uma ferramenta importante para auxiliar a equipe ao atendimento as populações vulneráveis a Infecções Sexualmente Transmissíveis (IST) orientando os pacientes a prática de sexo seguro com seus parceiros, avaliando os exames de rotina em relação ao nível da carga viral e o sistema imunológico do paciente.

Dessa forma, o estudo de Zanardo et al. (2018), as fragilidades nas práticas do enfermeiro revelam falha no sistema público de saúde, dificultando o acesso aos pacientes aos testes rápidos, informações sobre prevenção ligados aos aspectos sociopolíticos e econômico. Segundo Reis et al. (2020), mesmo com a evolução da tecnologia ao acesso de informações sobre as práticas sexuais de forma segura, os usuários têm receio ao assunto pela falta de conhecimento ligado a questão cultural, gerando duvidas e falta do autocuidado.

Um estudo realizado por Meirelles e Coelho (2018), apontem que os profissionais de saúde colocam em destaque a meta 90\% diagnósticos, 90\% pacientes iniciando a TARV, 90\% controle da carga viral indetectável, priorizando a capacitação dos profissionais, dando um suporte em materiais e insumos para realização do diagnóstico, tendo um olhar na atenção de qualidade às PVHAs. O estudo mostra que os enfermeiros atuam no aconselhamento, pois se torna uma habilidade interligada a escuta ativa com paciente, mostrando que há um desafio para esses profissionais (Da Silva et al., 2018).

Para Da Silva et al. (2020), as barreiras que os enfermeiros relatam para a implementação da assistência aos pacientes tem uma ligação com a gestão da unidade básica de saúde e sistema público na entrega dos insumos e materiais que auxiliam na prevenção e tratamento, a relação da estrutura física que implica diretamente aos testes rápidos, prejudicando no rastreamento e controle, a segurança do profissional na aplicação do aconselhamento pré e pós-teste, sobrecarga que atrapalha o planejamento e realização de ações educativas. Sendo assim Da Silva et al. (2017), justifica a necessidade que o enfermeiro atue na atenção primária, promovendo ações que trabalhe a prática do sexo seguro, sinais e sintomas da infecção, tratamento da doença no uso dos antirretrovirais de forma continua, orientação sobre a qualidade de vida das pessoas vivendo com HIV/Aids, tendo consequência da diminuição das comorbidades secundárias. 


\section{Conclusão}

Os dados analisados neste estudo mostraram as principais dificuldades vivenciadas na assistência do enfermeiro às pessoas que vivem com HIV/Aids na atenção básica que, por conseguinte, sugerem a necessidade de intensificar a capacitação do profissional frente ao acompanhamento desde o aconselhamento até a continuidade do tratamento com a terapia antirretroviral.

Nesse sentido, os autores discutiram diversas questões, tais como: a indisponibilidade de materiais que auxiliam na educação em saúde, os testes rápidos para a realização do diagnóstico, a estrutura física para guardar o material, a sobrecarga dos enfermeiros, o medo dos profissionais e pacientes, as questões socioculturais, o estigma gerando o baixo nível de conhecimento sobre a infecção por HIV e questões emocionais, como a negação após o diagnóstico positivo provocando o abandono da TARV.

Diante do exposto, pôde-se notar que os artigos mostram as falhas do sistema público de saúde frente a atenção primária ligadas à logística de insumos e matérias limitando a assistência e prejudicando a facilidade ao acesso de um serviço de qualidade. Os conhecimentos adquiridos com este estudo podem servir de base para pesquisas futuras na avaliação dos pontos que atrapalham a assistência, as falhas na gestão em saúde publica, investimentos para os profissionais de saúde em técnica do aconselhamento e conhecimento na abordagem ao paciente e efetividade na promoção à saúde e qualidade de vida.

\section{Referências}

Alexandre, L. P. (2015). Os avanços e desafios do SUS nas duas décadas de existência. In: Aguiar, Z. N. SUS Sistema Único de Saúde; Antecedentes, percursos, perspectivas e desafios. 2ed. São Paulo: Martinari. cap. 7, p. 149-65.

Brasil. Ministério Saúde (2014). Manejo do HIV na Atenção Básica. http://www.aids.gov.br/pt-br/gestores/manejo-do-hiv-na-atencao-basica..

Brasil. Ministério Saúde. (2017). Cuidado integral às pessoas que vivem com HIV pela Atenção Básica. Brasília. http://bvsms.saude.gov.br/bvs/publicacoes/cuidado_integral_hiv_manual_multiprofissional.pdf.

Brasil. Ministério da Saúde. (2013). Aids / HIV: o que é, causas, sintomas, diagnóstico, tratamento e prevenção. Brasília. http://www.saude.gov.br/saude-dea-z/aids-hiv.

Eriksen, M. B. \& Frandsen, T. F. (2018). The impact of patient, intervention, comparison, outcome (PICO) as a search strategy tool on literature search quality: a systematic review. Journal of The Medical Library Association. 106(4), 420-431.

Greco, D. B. (2016). Trinta anos de enfrentamento à epidemia da Aids no Brasil,1985-2015. Rev. Ciência \& Saúde Coletiva, Rio de Janeiro. 21(5), 1553-64. https://doi.org/10.1590/1413-81232015215.04402016.

De Lima, I. C. V., Galvão, M. T. G., Guedes, D. Da S., de Freitas, P. C. A., Farias, O. de O. \& da Cunha, G. H. (2020). Análise das necessidades de ajuda de homens com HIV que fazem sexo com homens. Rev Esc Enferm USP, 54, 01-07. https://doi.org/10.1590/S1980-220X2019010303650.

Meirelles, B. H. S. \& Coelho, B. (2019). Compartilhamento do cuidado da pessoa com HIV/Aids: olhar direcionado ao adulto jovem. Rev Bras Enferm [Internet], 72(5), 1409-16. https://doi.org/10.1590/0034-7167-2018-0248.

Melo, E. A., Maksud, I. \& Agostini, R. (2018). Cuidado, HIV/Aids e atenção primária no Brasil: desafio para a atenção no Sistema Único de Saúde. Rev. Panam Salud Publica, 42, 01-05. https://doi.org/10.26633/RPSP.2018.151.

Melo, L.S., Ercole, F. F. \& Alcoforado, C. L. G. C. (2014). Revisão Integrativa versus Revisão Sistemática. Rev. Min. Enferm, 18(1). http://www.dx.doi.org/10.5935/1415-2762.20140001.

Paula, A. M. B., Haika, D. S. A., Holzmann, A. P. F., Gomes, L. M. X. \& Barbosa, T. L. de A. (2015). Aconselhamento em doenças sexualmente transmissíveis na atenção primária: percepção e prática profissional. Acta Paul Enferm, 28(6), 531-8. https://doi.org/10.1590/1982-0194201500089.

Organização Mundial de Saúde (OMS). (2017). Folha informativa-HIV/aids. Brasília.

https://edisciplinas.usp.br/pluginfile.php/5624379/mod_resource/content/1/OPAS_OMS\%20Brasil\%20-\%20Folha\%20informativa\%20-\%20HIV_aids.html.

Quirino, E. M. B., Pinho, C. M. P., Araújo, W. J. \& Andrade, M. S. (2017). Percepção de enfermeiros executores de teste rápido em Unidades Básicas de Saúde. Rev Bras Enferm [Internet]. 71(1), 676-81. http://dx.doi.org/10.1590/0034-7167-2017-0298.

Reis, R. K., de Oliveira, L. B., Ponte, P. S., Magalhães, R. de L. B., Gir1, E. \& Costa, C. R. B. (2020). Parceria sexual entre pessoas vivendo com HIV: gerenciando as diferenças sorológicas. Enfermería Global,19(2), 507-518. https://doi.org/10.6018/eglobal.384261.

Rocha, K. B., Moro, L. M., Ferreira, G. S. \& Ew, R. de A. (2018). Estigma e teste rápido na atenção básica: percepção de usuários e profissionais. Rev Bras Promoç Saúde, 31(3), 1-11. https://doi.org/10.5020/18061230.2018.7463. 
Research, Society and Development, v. 10, n. 6, e55410616160, 2021

(CC BY 4.0) | ISSN 2525-3409 | DOI: http://dx.doi.org/10.33448/rsd-v10i6.16160

Santos, A.T.O, Cardoso, A. C. C., Bispo, T. C. F. \& Almeida, T. A. (2012). Novos avanços relacionados ao HIV/AIDS. Rev. Enfermagem Contemporânea, 1(1), 80-102. http://dx.doi.org/10.17267/2317-3378rec.v1i1.45.

Serra, M. A. P., Pereira, I. L., Nogueira, J. de A., Chaves, R. B., Bezerra, V. P. \& de Almeida, S. A. (2016). Ações de prevenção do hiv e de promoção à saúde no contexto da aids pela estratégia saúde da família em João Pessoa-PB. Cienc Cuid Saude, 15(2), 343-349. https://doi.org/10.4025/cienccuidsaude.v15i2.28900.

Silva, R. A. R., Ferreira, K. da S., Lucena, I. de A., Duarte, F. H. da S., Costa, R. H. S. \& Braz, L. C. da B. (2017). Pessoas vivendo com Aids: associação entre diagnósticos de enfermagem e características sociodemográficas/clínicas. Rev Bras Enferm [Internet], 71(5), 2684-91. https://doi.org/10.1590/00347167-2017-0420.

Silva, G. A., Pimentel, F. E., Farah, B. F. \& Alonso, C. da S. (2020). Percepções de pessoas que vivem com HIV/Aids sobre o cuidado oferecido na atenção básica. Rev Enferm Atenção Saúde [Online], 9(2), 75-87. https://doi.org/10.18554/reas.v9i2.3961.

Silva, Y. T., Da Silva, L. B. \& Ferreira, S. M. S. (2018). Práticas de aconselhamento em Infecções Sexualmente Transmissíveis/Aids: perspectiva das profissionais de saúde. Rev Bras Enferm [Internet], 72(5), 1200-7. http://dx.doi.org/10.1590/0034-7167-2018-0176.

Sousa, L. P., Mendes, L. M. C., Monteiro, R. S., do Nascimento, V. B. \& Neto, A. S. Da S. (2020). Atuação da equipe de enfermagem no teste rápido antiHIV. Rev Enfermagem UFPE, 14, 01-06. doi: 10.5205/1981-8963.2020.244420.

Suto, C. S. S., Porcino, C., Paiva, M. S., Marques, S. C., Coelho, E. de A. C. \& Cabral, L. da S. (2020). Mulheres de diferentes gerações que vivem com HIV: representações sociais sobre sexualidade. Rev Esc Enferm USP, 54, 01-09. https://doi.org/10.1590/S1980-220X2019018303658.

Teixeira, E., Rodrigues, I. L. A., Palmeira, I. P., Machado, T. D. P., de Carvalho, D. S \& Brasil, G. de B. (2019). Desenvolvimento participativo de tecnologia educacional em contexto HIV/Aids. Rev Min Enferm., 23, 01-07. http://www.dx.doi.org/10.5935/1415-2762.20190084.

Teles, M. V. A. de O., Suto, C. S. S., Silva, D. de O., Porcino, C. A., Oliveira, D. S. \& Junior, J. A. A. (2019). Representações sociais de trabalhadores da atenção básica acerca do teste rápido. Rev Min Enferm, 23, 01-07. http://www.dx.doi.org/10.5935/1415-2762.20190021.

UNAIDS. (2020). Informações básicas: Sobre o HIV e a AIDS. https://unaids.org.br/informacoes-basicas/.

Yonekura, T., Sangaleti, C., Silva, D. R. A. D., Soares, C. B., Peduzzi, M. \& Hoga, L. A. K. (2014). Revisão integrativa: conceitos e métodos utilizados na enfermagem. Rev. esc. enferm. USP, 48(2), 335-345. https://doi.org/10.1590/S0080-6234201400002000020.

Valença, C. N., da Silva, R. A. R. \& da Silva, I. T. S. (2017). Cartografia da implementação do teste rápido anti-HIV na Estratégia Saúde da Família: perspectiva de enfermeiros. Esc Anna Nery, 21(4), 01-08. https://doi.org/10.1590/2177-9465-EAN-2017-0019.

Zanardo, G. L. de P., Rocha, K. B., Adolfo Pizzinato, A., Moro, L. M. \& Ew. R. de A. S. (2018). Aconselhamento na perspectiva de profissionais da atenção básica: desafios na descentralização do teste rápido HIV/Aids. Cienc. Psicol. [online], 12(1), 67-78. http://dx.doi.org/10.22235/cp.v12i1.1597. 